\title{
The Economic Effects of Restrictions on Government Budget Deficits
}

\author{
Ghiglino, Christian; Shell, Karl
}

Document Version

Final published version

Publication date:

1998

License

CC BY-NC-ND

Citation for published version (APA):

Ghiglino, C., \& Shell, K. (1998). The Economic Effects of Restrictions on Government Budget Deficits. Department of Economics. Copenhagen Business School. Working Paper / Department of Economics.

Copenhagen Business School No. 3-98

Link to publication in CBS Research Portal

\footnotetext{
General rights

Copyright and moral rights for the publications made accessible in the public portal are retained by the authors and/or other copyright owners and it is a condition of accessing publications that users recognise and abide by the legal requirements associated with these rights.

Take down policy

If you believe that this document breaches copyright please contact us (research.lib@cbs.dk) providing details, and we will remove access to the work immediately and investigate your claim.
} 


\section{Institut for Nationaløkonomi}

Handelshøjskolen i København

Working paper 3-98

THE ECONOMIC EFFECTS OF RESTRICTIONS ON GOVERNMENT BUDGET DEFICITS

Christian Ghiglino $\quad$ Karl Shell 


\title{
The Economic Effects of Restrictions on Government Budget Deficits
}

\author{
Christian Ghiglino \\ Department of Economics \\ Copenhagen Business School \\ Nansensgade 19, 5 \\ DK-1366 Copenhagen, Denmark \\ cg.eco@cbs.dk
}

\author{
Karl Shell \\ Department of Economics \\ 402 Uris Hall \\ Cornell University \\ Ithaca, NY 14853-7601 USA \\ ks22@cornell.edu
}

January 23, 1998

\begin{abstract}
Headnote
In overlapping-generations economies with perfect financial markets and lumpsum taxation, restrictions on the government budget deficits do not limit the set of achievable allocations. For economies in which tax instruments are distortionary and limited in number, deficits are irrelevant only in the unrealistic case in which the number of tax instruments is large relative to the number of policy goals. In particular, if the government can use only anonymous consumption taxes, then achieving the prescribed deficits without changing the equilibrium allocation will typically be impossible when the number of consumers exceeds the number of commodities. A similar result holds if consumer credit is (exogenously) restricted. Surprisingly, in this case, distortionary taxes may be more likely than lump-sum taxes to lead to the irrelevance of government deficits. Journal of Economic Literature Classification Numbers: D51, D91, E32.
\end{abstract}

Keywords: Balanced Budget, Balanced-Budget Amendment, Burden of the Public Debt, Comparative Statics, Consumption Taxes, Credit Restrictions, Distortionary Taxes, Economic Policy, Government Budget Deficit, Maastricht Treaty, Optimal Taxation, Overlapping Generations. 
Correspondent: Karl Shell, Department of Economics, 402 Uris Hall, Cornell University, Ithaca, NY 14853-7601 USA. E-mail: ks22@cornell.edu; telephone: 607-255-5277; fax: 607-255-8838.

Running Head: Government Deficits 


\section{Introduction}

It has been proposed that the United States constitution be amended to make it unlawful for there to be a deficit in the federal government's budget. In some states in the United States, there are already constitutional prohibitions or restrictions on government deficits. The Maastricht Treaty calls for fines to be levied on countries in the European Union that incur budget deficits beyond the prescribed limits (currently $3 \%$ of GDP). Some governments are already obliged to limit their budget deficits by the terms of their loan agreements with international agencies.

What are the economic effects of restrictions on government budget deficits? The popular wisdom is that these restrictions do matter, but there is debate about their desirability. The popular view is supported by empirical evidence that government budget deficit restrictions are effective in reducing government expenditure. See, for example, Alesina et al. (1996), Poterba (1996), and Bohn and Inman (1996), studies based on comparisons across the states of the U.S. On the other hand, the thrust of the existing theoretical literature is that the deficit restrictions are ineffective in the sense that the set of perfect-foresight equilibrium allocations is independent of the sequence of government budget deficits. See, for example, Auerbach and Kotlikoff (1987), Kelly (1991), and Kotlikoff (1993). These theoretical results are mainly based on models with only one (representative) consumer per generation.

In the present paper, we take a fresh look at the theory of budget-deficit restrictions. For the analysis, we adopt a pure-exchange overlapping-generations model with several consumers per generation and several commodities per period. We allow for distortionary taxes, focusing on the case of consumption taxes. We also allow for the fact that tax schedules cannot be made perfectly individual-specific. For example, it might be the case that each consumer in a given generation must face the same tax schedule, possibly because of limits on the information of the tax authority or possibly for considerations of fundamental fairness. In this sense, we allow for (at least partially) anonymous taxation.

We apply the approach of Diamond and Mirrlees (1971) [see also Mirrlees (1976)] to modeling government behavior. It is assumed that the government knows the distribution of individual characteristics within a given consumer class (say, the individuals of a given generation), but it either does not know or cannot act upon the characteristics of any particular individual within this class. It is also assumed that - even though the government knows the distribution of commodities in fine detail - it cannot tax commodities in the same commodity class at different rates.

The advantage of lump-sum taxes (if they are feasible) is that they are nondistortionary. If perfectly personalized lump-sum taxes were feasible, then every Pareto optimal allocation could be decentralized. If perfectly personalized taxes are not available, then consumption taxes while distortionary have some potential advantages for income

redistribution over lump-sum taxes. Everyone in the same tax class must get the same 
lump-sum transfer or tax. Everyone in the same tax class must face the same consumption tax rates, but by varying the rates over the commodity tax classes, the government is typically able to "redistribute income" within a given consumer tax class. Of course, if the taxes are distortionary, such redistribution of income is not costless.

For completeness, we show that if there are lump-sum taxes, then the set of equilibrium allocations is independent of the sequence of budget deficits. Hence, in this case, restrictions on the deficits are irrelevant. This is in accord with the existing results of Kelly (1991) and others, but our result is somewhat stronger in that we have several commodities per period, distortionary tax instruments in addition to the lump-sum instruments, and restrictions that tax rates be identical in the same consumer tax class and in the same commodity tax class. The reasoning behind this so-called irrelevance result is clear. The government's borrowing and lending is restricted in every period. These restrictions are not binding because the government can in effect borrow from (or lend to) consumers whose own credit is unrestricted by increasing (decreasing) their taxes in their youth while "repaying them" ("collecting from them") in their old age in such a way as to keep total lifetime taxation unchanged. Of course, even if only one consumer class faces perfect credit markets there would be deficit restriction irrelevance with lump-sum taxation, since the government needs only one such consumer per generation to meet the deficit targets.

The situation is different if neither lump-sum taxes nor perfectly personalized taxes are available. We analyze an economy in which the only taxes are (distortionary) proportional consumption taxes. In this economy, the relevance of the restrictions on the government budget deficits depends crucially on the number of consumers per generation relative to the number of independent tax instruments per period. The reason for this is that, when too few tax instruments are available, meeting the restrictions on the budget deficit is likely to necessitate redistributions of wealth. The government's allocative potency is further limited by the fact that in equilibrium the pre-tax and post-tax prices of each good must be nonnegative. Hence, even in the unrealistic case where the number of instruments is large relative to the number of individuals, large changes in the restrictions on the government budget deficit might affect the set of equilibrium allocations. The possibility for complete budget irrelevance is further reduced by problems associated with the infinite horizon in the overlapping-generations model. The government might be able to keep a prescribed deficit sequence for a finite number of periods (no matter how many), but might be unable to commit to the full infinite sequence of deficits while supporting the original allocation of resources.

The relevance of government deficit restrictions is also investigated in economies in which some consumers face credit constraints. For economies with lump-sum taxes and consumer borrowing constraints, deficit restrictions are likely to be relevant unless the government can "identify" a consumer in each generation whose borrowing is unrestricted. For economies with only consumption taxes, the conditions for irrelevance are altered by the consumer borrowing restrictions but they still depend on the number of instruments 
relative to the number of consumer types. Irrelevance of deficit restrictions is less unlikely with consumption taxation rather than lump-sum taxation, because commodity taxes can help the government in providing liquidity to some member of a consumer class. Formal techniques of this study are also useful for asking whether or not it is possible to find a fiscal policy that eliminates individual consumer liquidity constraints while meeting a government deficit requirement. This can only be feasible if the deficit in the first period is unrestricted.

We introduce the model in section 2. Feasible fiscal policies are defined in section 3. Section 4 is on equilibrium. Section 5 contains our analysis of the economy with lump-sum taxation. Sections 6 and 7 contain the heart of our analysis. Section 6 is on consumption taxes, while Section 7 is on borrowing restrictions. An important caveat is in Section 8, our concluding remarks. In the text our "proofs" are careful "counting arguments" (of equations and unknowns). The full (matrix rank) analysis is in the appendix.

\section{The basic model}

We employ a pure-exchange overlapping-generations model in which there are $n$ different consumers per generation and $\ell$ perishable commodities per period. We suppose without loss of generality that consumers live for two periods. The government collects taxes and distributes transfers. In the present paper, we focus on two types of instruments: (nondistortionary) lump-sum taxes and (distortionary) consumption taxes. The full spectrum of these taxes is typically not available to the government: individuals in the same consumer tax class must face the same tax schedule; i.e. taxation must be anonymous within a given class of individuals. The two limiting cases are perfectly individualized taxation (where each consumer tax class contains only one individual) and perfectly anonymous taxation (where each individual is in the same consumer tax class). The government is also constrained to set the same tax rate for each commodity in the same commodity class. The two limiting cases are perfect commodity discrimination (where each commodity tax class contains only one commodity) and total lack of commodity discrimination (where there is only one commodity tax class per period).

For simplicity, we assume that public consumption of commodities is exogenously determined. Public consumption can then be set at zero without loss of generality.

In most of the paper, it is assumed that capital markets (borrowing and lending markets) are perfect. In Section 7, we treat the case in which individuals face (exogenously given) restrictions on their credit.

Our set-up is based on the Samuelson (1958) overlapping-generations model presented in Balasko and Shell $(1980,1981,1986)$, but new tax instruments must be defined. As in Balasko and Shell (1981), let $m_{t h}^{s} \in \mathbb{R}$ be the lump-sum money transfer to consumer $h$ of generation $t$ in period $s$; if $m_{t h}^{s}$ is negative, then the consumer is paying a lump-sum tax. We add consumption taxes. Let $\tau_{t h}^{s i} \in \mathbb{R}$ be the tax rate in own commodity units levied 
on consumer $h$ of generation $t$ on his consumption of commodity $i$ in period $s$; if $\tau_{t h}^{s i}$ is negative then this consumption activity is being subsidized.

Let $x_{t h}^{s}=\left(x_{t h}^{s 1}, \ldots, x_{t h}^{s i}, \ldots, x_{t h}^{s l}\right) \in \mathbb{R}_{++}^{\ell}$ be the vector of consumption in period $s$ by individual $h$ of generation $t$ and $\omega_{t h}^{s}=\left(\omega_{t h}^{s 1}, \ldots, \omega_{t h}^{s i}, \ldots, w_{t h}^{s \ell}\right) \in \mathbb{R}_{++}^{\ell}$ be the vector of endowments in period $\mathrm{s}$ of individual $h$ from generation $t$ for $t=0,1, \ldots, s=1,2, \ldots$, and $h=1, \ldots, n$. Let $m_{t h}^{s} \in \mathbb{R}$ be the money transfer in period $s$ to consumer $h$ of generation $t$, and $\tau_{t h}^{s}=\left(\tau_{t h}^{s 1}, \ldots, \tau_{t h}^{s i}, \ldots, \tau_{t h}^{s l}\right) \in \mathbb{R}^{\ell}$ be the vector of consumption tax rates in period $s$ for consumer $h$ of generation $t$. Consumers from generation 0 are alive in period 1 , while consumers from generation $t(t=1,2, \ldots$,$) are alive in periods t$ and $t+1$. Hence it is convenient to define the following vectors:

$$
\begin{array}{cl}
x_{0 h}=x_{0 h}^{1} \in \mathbb{R}_{++}^{\ell}, & x_{t h}=\left(x_{t h}^{t}, x_{t h}^{t+1}\right) \in \mathbb{R}_{++}^{2 \ell}, \\
\omega_{0 h}=\omega_{0 h}^{1} \in \mathbb{R}_{++}^{\ell}, & \omega_{t h}=\left(\omega_{t h}^{t}, \omega_{t h}^{t+1}\right) \in \mathbb{R}_{++}^{2 \ell}, \\
m_{0 h}=m_{0 h}^{1} \in \mathbb{R}, \quad & m_{t h}=\left(m_{t h}^{t}, m_{t h}^{t+1}\right) \in \mathbb{R}^{2}, \\
\text { and } & \\
\tau_{0 h}=\tau_{0 h}^{1} \in \mathbb{R}^{\ell}, \quad \tau_{t h}=\left(\tau_{t h}^{t}, \tau_{t h}^{t+1}\right) \in \mathbb{R}^{2 \ell} .
\end{array}
$$

Let $p^{s}=\left(p^{s 1}, \ldots, p^{s i}, \ldots, p^{s \ell}\right) \in \mathbb{R}_{++}^{\ell}$ be the vector of present (before-tax) prices for commodities available in period $t$ and let

$$
q_{t h}^{s}=\left(q_{t h}^{s 1}, \ldots, q_{t h}^{s i}, \ldots, q_{t h}^{s \ell}\right) \in \mathbb{R}_{++}^{\ell}
$$

be the present after-tax vector of commodity prices for consumer $h$ of generation $t$ in period $s$. Define the after-tax present price vectors facing consumers by

$$
\begin{aligned}
& q_{0 h}= q_{0 h}^{1}=p^{1}+\tau_{0 h} \in R_{++}^{\ell} \\
& \text { and } \\
& q_{t h}=\left(q_{t h}^{t}, q_{t h}^{t+h}\right)=\left(p^{t}, p^{t+1}\right)+\left(\tau_{t h}^{t}, \tau_{t h}^{t+1}\right) \in R_{++}^{2 \ell}
\end{aligned}
$$

for $h=1, \ldots, n$. Then define the following quantity and price sequences: $x=\left(\left(x_{0 h}\right)_{h=1}^{h=n}, \ldots\right.$, $\left.\left(x_{t h}\right)_{h=1}^{h=n}, \ldots\right), \omega=\left(\left(\omega_{0 h}\right)_{h=1}^{h=n}, \ldots,\left(\omega_{t h}\right)_{h=1}^{h=n}, \ldots\right), p=\left(p^{1}, \ldots, p^{t}, \ldots\right), m=\left(\left(m_{0 h}\right)_{h=1}^{h=n}, \ldots\right.$ $\left.\left(m_{t h}\right)_{h=1}^{h=n}, \ldots\right), \tau=\left(\left(\tau_{0 h}\right)_{h=1}^{h=n}, \ldots,\left(\tau_{t h}\right)_{h=1}^{h=n}, \ldots\right)$ and $q=\left(\left(q_{0 h}\right)_{h=1}^{h=n}, \ldots,\left(q_{t h}\right)_{h=1}^{h=n}, \ldots\right)$.

We assume that the preferences of consumer $h$ from generation $t$ can be described by the utility function $u_{t h}$ defined over the consumption set of all strictly positive $x_{t}$ 's (i.e. $\mathbb{R}_{++}^{\ell}$ or $\mathbb{R}_{++}^{2 \ell}$ ) with the properties: 
(2.2) $u_{t h}$ is twice differentiable with strictly positive first-order derivatives and with corresponding negative definite Hessian

and

(2.3) the closure of every indifference surface of $u_{t h}$ is in the consumption set (i.e. $\mathbb{R}_{++}^{\ell}$ or $R_{++}^{2 \ell}$ ).

These rather standard assumptions simplify the comparative statics. See Balasko and Shell $(1980,1981)$ for their application in overlapping-generations models. Note that we have also assumed that the endowment of the consumer lies in his consumption set, i.e. we have $\omega_{t h}$ is in $\mathbb{R}_{++}^{\ell}$ or $\mathbb{R}_{++}^{2 \ell}$.

The behavior of consumer $h(h=1,2, \ldots, n)$ from generation $t(t=1,2, \ldots)$ is then described by:

$$
\begin{aligned}
& \text { maximize } u_{t h}\left(x_{t h}^{t}, x_{t h}^{t+1}\right) \\
& \text { subject to } \\
& q_{t h}^{t} \cdot x_{t h}^{t}+p^{t m} x_{t h}^{t m}=p^{t} \cdot \omega_{t h}^{t}+p^{t m} m_{t h}^{t} \\
& q_{t h}^{t+1} \cdot x_{t h}^{t+1}+p^{t+1, m} x_{t h}^{t+1, m}=p^{t+1} \cdot \omega_{t h}^{t+1}+p^{t+1, m} m_{t h}^{t+1} \\
& x_{t h}^{t+m}+x_{t h}^{t+1, m}=0 \text { and } x_{t h}=\left(x_{t h}^{t}, x_{t h}^{t+1}\right) \in \mathbb{R}_{++}^{2 \ell}
\end{aligned}
$$

where $x_{t h}^{s m} \in \mathbb{R}$ is the net addition to his money holdings in period $s$ by consumer $h$ of generation $t$. The last equation in (2.4) is the requirement that the end of life money holding be zero.

If borrowing and lending markets are perfect, then an equilibrium (no arbitrage) condition is that the present price of money be constant, i.e.,

$$
p^{t m}=p^{t+1, m}=p^{m} \in \mathbb{R}_{+}
$$

The nominal (coupon) rate of interest on money is assumed without loss of generality to be zero. Hence the only return on holding money is the capital gain relative to commodities. Condition (2.5) is thus that money appreciate in value relative to any commodity at the commodity rate of interest. Condition (2.5) allows us to rewrite (2.4) as [see Balasko and Shell (1981)]: 


$$
\begin{aligned}
& \text { maximize } u_{t h}\left(x_{t h}^{t}, x_{t h}^{t+1}\right) \\
& \text { subject to } \\
& q_{t h}^{t} \cdot x_{t h}^{t}+q_{t h}^{t+1} \cdot x_{t h}^{t+1} \\
& =p^{t} \cdot \omega_{t h}^{t}+p^{t+1} \cdot \omega_{t h}^{t+1}+p^{m} m_{t h}^{t}+p^{m} m_{t h}^{t+1}
\end{aligned}
$$

for $h=1,2, \ldots, n$ and $t=1,2, \ldots$. Hence the transfers $m_{t h}=\left(m_{t h}^{t}, m_{t h}^{t+1}\right) \in \mathbb{R}^{2}$ affect the behavior of the consumer only through the lifetime transfer $\mu_{t h}=m_{t h}^{t}+m_{t h}^{t+1} \in \mathbb{R}$.

In what follows, we assume that the price of money is positive. Then because of the absence of money illusion, we can normalize taxes and transfers so that $p^{m}=1$ without loss of generality.

It remains to describe the behavior of the older generation $(t=0)$ in period 1 . Consumer $0 h$ maximizes his utility subject to his one-period budget constraint:

$$
\begin{aligned}
& \operatorname{maximize} u_{O h}\left(x_{0 h}^{1}\right) \\
& \text { subject to } \\
& q_{O h}^{1} \cdot x_{0 h}^{1}+x_{0 h}^{1 m}=p^{1} \cdot \omega_{0 h}^{1}+m_{0 h}^{1} \\
& x_{0 h}^{1 m}=0, \\
& \text { and } \\
& x_{0 h}^{1} \in \mathbb{R}_{++}^{\ell} .
\end{aligned}
$$

\section{Feasible fiscal policies}

In the simplest case, a fiscal policy could be any sequences of lump-sum transfers $m$ and commodity tax rates $\tau$. This would be the case of full fiscal potency. There are, however, typically further restrictions on the powers of the government. It is unlikely that the tax authorities can differentiate individuals sufficiently to use the full range of personalized taxation. Some personalizations of the schedules might require too much detailed information about individuals, might be very costly to administer ${ }^{1}$, or might be deemed to be unfair.

\footnotetext{
${ }^{1}$ See Heller and Shell (1974) for the effects on tax policy of costs of tax administration.
} 
On the other hand, governments can and do base taxes and other policies on demographic characteristics. Age and family size are frequently used in tax policies. To qualify for a government retirement transfer, one must meet an age test. Tax rates for withdrawals from private retirement plans in the U.S. depend on the age of the withdrawer. For U.S. personal income taxation, the "personal exemption" (from gross income) is doubled for those over 65 years; other deductions and exemptions (from income) are based on family size. In Europe, the fare on public transportation is reduced for older people and for people from "large families." And so on.

We suppose that the set of consumers $\{1, \ldots, h, \ldots n\}$ is partitioned into $N \leq n$ consumer tax classes $C_{1}, \ldots, C_{h}, \ldots, C_{N}$. If $N=n$, then complete individualization of taxes would be possible. If $N=1$, every consumer within the same generation would face the same $m$ 's and $\tau$ 's. Some assumptions are implicit in our formulation. The partition is stationary: it is the same for each generation. Furthermore, individuals remain in the same consumer tax class for their lifetimes. Neither of these assumptions affect our results. It is also assumed that the young and old are never in the same tax class. Relaxing this last assumption does affect our analysis. Being able to tax the young differently from the old plays an important role in our proofs and examples.

There are other restrictions on government tax policies. It is in some instances impossible or at least very costly for the government to tax "nearby" commodities at different rates. Imagine taxing white bread differently from whole wheat bread. This might impose unreasonably high compliance costs on the bakers, while imposing unreasonably high administrative cost on the tax authority.

We suppose therefore that the set of commodities $\{1, . ., i, \ldots, \ell\}$ in any period is partitioned into $L \leq \ell$ commodity tax classes, $K_{1}, \ldots, K_{I}, \ldots, K_{L}$. If $L=1$, then at any given time all commodities must be taxed at the same rate. If $L=\ell$, then the restriction to commodity tax classes is not binding. We formalize the notion of these restrictions on government policy in the next definition.

3.1 Definition A feasible fiscal policy $\phi=(m, \tau)$ is a sequence of lump-sum transfers $m$ and a sequence of commodity tax rates $\tau$ that satisfies

(1) $m_{t h}^{s}=m_{t h^{\prime}}^{s}$ and $\tau_{t h}^{s}=\tau_{t h^{\prime}}^{s}$ for $t=0,1, \ldots$ and $s=1,2, \ldots$ for every $h$ and $h^{\prime}$ in the same consumer tax class $C_{H}$ for $H=1, . ., N$

and

(2) $\tau_{t h}^{s i}=\tau_{t h}^{s i}$ for $t=0,1, \ldots, s=1,2, \ldots, i=1, \ldots, \ell$ and $i^{\prime}=1, \ldots, \ell$ for every $i$ and $i$ in the same commodity tax class $K_{I}, I=1, \ldots, L$.

The set of all feasible fiscal policies is denoted by $\Phi$. If only lump-sum transfers are available, then a feasible fiscal policy is denoted by the sequence $m$; and the set of feasible 
fiscal policies is denoted by $\mathcal{M}$. If only consumption taxes are available, then a feasible fiscal policy is denoted by the sequence $\tau$ and the set of feasible fiscal policies by $\mathcal{T}$.

Since government expenditures are zero, the government budget deficit is the sum of transfers less the sum of taxes. The government budget deficit in period $t(t=1,2, \ldots)$ is

$$
\sum_{h=1}^{h=n}\left[m_{t-1, h}^{t}+m_{t h}^{t}-\sum_{i=1}^{i=\ell}\left(\tau_{t-1, h}^{t i} x_{t-1, h}^{t i}+\tau_{t h}^{t i} x_{t h}^{t i}\right)\right] .
$$

If the constitutional restriction on the budget deficit is satisfied, then we have

$$
\sum_{h=1}^{h=n}\left[m_{t-1, h}^{t}+m_{t h}^{t}-\sum_{i=1}^{i=\ell}\left(\tau_{t-1, h}^{t i} x_{t-1, h}^{t i}+\tau_{t h}^{t i} x_{t h}^{t i}\right)\right]=\delta^{t}
$$

for $t=1,2, \ldots$, where $\delta^{t} \in \mathbb{R}$ is the deficit restriction for period $\mathrm{t}$ and the sequence $\delta$ is defined by $\delta=\left(\delta^{1}, \delta^{2}, \ldots, \delta^{t}, \ldots\right)$. The restriction $(3.2)$ is complicated when there are consumption taxes. The m's enter (3.2) in a relatively sinple way, but the $\tau$ 's interact with individual consumptions in determining whether (3.2) is satisfied. In this economy, the government finances its debt by "printing" money. Let $M^{t}$ be the money supply in period $\mathrm{t}(t=1,2, \ldots)$. If we assume $M^{0}=0$, then $M^{t}$ is equal to the government debt and $\Delta M^{t}=M^{t}-M^{t-1}$ is equal to the government deficit in period t.

\section{Equilibrium}

We maintain throughout this paper some very strong assumptions. We suppose perfectforesight on the part of consumers and the government. We also suppose that the government is able to perfectly commit to its announced fiscal policy.

Next we define equilibrium.

4.1 Definition Given the sequence of endowments $\omega$, the feasible fiscal policy $\phi \in$ $\Phi=\mathcal{M} \times \mathcal{T}$, the behavior of consumers described by the systems (2.4) and (2.6), the numeraire choice yielding $p^{11}=1$, the (further) monetary normalization yielding $p^{m}=1$ and the deficit sequence $\delta=\left(\delta^{1}, \ldots, \delta^{t}, \ldots\right)$, a constitutional competitive equilibrium is defined by two positive price sequences, $p$ and $q$, the allocation sequence $x$ such that markets clear, i.e. we have

$$
\sum_{h=1}^{h=n}\left(x_{t-1, h}^{t}+x_{t, h}^{t}\right)=\sum_{h=1}^{h=n}\left(\omega_{t-1, h}^{t}+\omega_{t, h}^{t}\right)
$$


and the (constitutional) deficit restriction (3.2) is satisfied for $t=1,2, \ldots$.

¿From Balasko and Shell (1980), one might expect that the existence of competitive equilibrium to be guaranteed in "nice" overlapping-generation models, but this does not extend to our Definition 4.1. There are two reasons that competitive equilibrium as defined above could fail to exist. The first reason is because of the restriction $p^{m}=1$, implying that we are seeking a proper monetary equilibria. For a proper monetary equilibrium to exist the fiscal policy $\phi$ must be bonafide ${ }^{2}$. The second reason is because of commodity taxation. It might not be possible to equilibrate supply and demand while maintaining the positivity of the two price sequences $p$ and $q$.

A discussion of the constitutional restriction (3.2) is in order. The leading example of restrictions on government deficits is the strict balanced-budget requirement: $\delta^{t}=0$ for $t=1,2, \ldots$. Most actual constitutions are based on aversion to positive deficits with typically no aversion to surpluses, so that a more realistic constraint would be in inequality form, namely $\Delta M^{t} \leq \delta^{t}$. The equality version, $\Delta M^{t}=\delta^{t}$, is simpler to work with and our basic results are not substatially affected by this choice. A slightly more serious worry is that these constraints might be stated in real terms, even perhaps that they might be based on economic performance as in the case of the Maastricht Treaty. This formulation would create some problems in notation, but it would not affect our results. Even so, the leading case is the strict balanced-budget restriction, $\delta=0$, which is the same in dollar or real terms.

Since the government faces the period-by-period "budget constraints" given by (3.2) rather than a single constraint, we are considering a general equilibrium economy in which participation in the financial markets is restricted. In this case, it is the government that cannot borrow freely. In most of the sequel, the other economic actors (the consumers) are unrestricted in their borrowing, but in Section 7 we impose on consumers borrowing restrictions similar to those imposed on the government.

In general, the restrictions (3.2) cannot be represented by simple restrictions on the set $\Phi$ of feasible tax and transfers, because revenues from the consumption taxes depend on the equilibrium allocation $x$. Indeed, because of the possible multiplicity of competitive equilibrium, it might be the case that - fixing preferences, endowments, and the fiscal policy - for some of the competitive equilibria the deficit restrictions (3.2) are satisfied, while for other competitive equilibria based on the same given parameters these deficit restrictions are not satisfied.

\footnotetext{
${ }^{2}$ Bonafidelity of the government constitutional policies is basic to our present problem, but we do not face this thorny problem head on. For the lump-sum tax case, see e.g. Balasko and Shell (1981, 1986, 1993) and Mitra (1988) for analyses that focus on bonafidelity.
} 


\section{Irrelevance of deficit restrictions in the benchmark economy}

For some overlapping-generations economies with a single (representative) consumer per generation, perfect borrowing and lending markets for consumers and a full range of lumpsum taxes and transfers, restrictions on the government budget have no impact on the set of equilibrium allocations. The reason for this irrelevance result is that in these economies only the present value of taxes and transfers, not their timing, matters to consumers. In this case, the government can "borrow" freely from taxpayers by adjusting the timing of individual taxes and transfers. See, for example, Auerbach and Kotlikoff (1987) and especially Kelly (1991).

The following Proposition extends the irrelevance result to economies with several (heterogeneous) consumers per generation, several commodities per period, (distortionary) consumption taxes and transfers in addition to (non-distortionary) lump-sum taxes and transfers, and restrictions on taxes to be "measurable" with respect to the consumer tax classes and with respect to the commodity tax classes.

\subsection{Proposition (Budget irrelevance if there are lump-sum taxes and transfers):} Let $x=\left(x_{0}, x_{1}, \ldots, x_{t}, \ldots\right)$ be an allocation that can be implemented as a competitive equilibrium with some feasible fiscal policy $\phi \in \Phi$ and with the resulting deficits given by the sequence $\delta$. Consider any other deficit sequence $\delta$. Then there is a feasible fiscal policy $\phi^{\prime} \in \Phi$ that implements as a competitive equilibrium the allocation $x$, but with the resulting deficit given by the sequence $\delta$.

Proof: We consider the least favorable case, the case in which taxes and transfers must be made completely anonymously within a given generation, i.e. the case of $N=1$.

The demand function $f_{t h}$ for consumer $h$ of generation $t(t=1,2, \ldots)$ maps after-tax consumer prices $\left(q_{t h}^{t}, q_{t h}^{t+1}\right) \in \mathbb{R}_{++}^{2 \ell}$ and wealth $w_{t h}=p^{t} \cdot \omega_{t h}^{t}+p^{t+1} \cdot \omega_{t h}^{t+1}+m_{t h}^{t}+m_{t h}^{t+1} \in \mathbb{R}_{++}$ into consumption $\left(x_{t h}^{t}, x_{t h}^{t+1}\right) \in \mathbb{R}_{++}^{2 \ell}$. In the case of generation 0 the demand function $f_{0 h}$ maps consumer prices $q_{0 h}^{1} \in \mathbb{R}_{++}^{\ell}$ and income $w_{0 h}=p^{1} \cdot \omega_{0 h}^{1}+m_{0 h}^{1} \in \mathbb{R}_{++}$into consumption $x_{0 h}^{1} \in \mathbb{R}_{++}^{\ell}$.

Therefore, $f_{t h}$ depends solely on $m_{t h}$ through the lifetime sum or present value $\mu_{t h}=$ $m_{t h}^{t}+m_{t h}^{t+1} \in \mathbb{R}$ for $t=1,2, \ldots$ and $\mu_{0 h}=m_{0 h}^{1} \in \mathbb{R}$. We claim that the budget specification is irrelevant because the sequence $\mu=\left(\mu_{0}, \mu_{1}, \ldots, \mu_{t}, \ldots\right)$ of lifetime transfers is compatible with any deficit restrictions $\delta=\left(\delta_{0}, \delta_{1}, \ldots, \delta_{t}, \ldots\right)$.

To establish this claim, consider the fiscal policy $\phi^{\prime}=(m, \tau)^{\prime}$ consistent with the budget restriction $\delta=\left(\left(\delta^{1}\right), . .,\left(\delta^{t}\right), \ldots\right)$ defined by

$$
\left(\tau_{t-1, h}^{t}\right)^{\prime}=\tau_{t-1, h}^{t}
$$




$$
\begin{aligned}
\left(\tau_{t h}^{t}\right)^{\prime} & =\tau_{t h}^{t}, \\
\left(m_{0 h}^{1}\right)^{\prime} & =m_{0 h}^{1}, \\
\left(m_{t h}^{t}\right)^{\prime} & =\left(\delta^{t}\right)^{\prime} / n-m_{t h}^{t},
\end{aligned}
$$

and

$$
\left(m_{t h}^{t+1}\right)^{\prime}=\mu_{t}-\left(m_{t h}^{t}\right)^{\prime}
$$

for $t=1,2, \ldots$ and $h=1, \ldots, n$. The tax policy $\phi^{\prime}$ is (completely) anonymous and it implements the allocation $x$ while meeting the sequence of deficit restrictions $\delta$.

¿From the proof of Proposition (5.1), it is very easy to see, and this is not surprising, that the irrelevance result still holds when consumption taxes are not included in the set of feasible tax instruments.

We conclude that if lump-sum taxes and transfers are included in the set of feasible instruments, one lump-sum tax instrument per period is sufficient to make the budget restriction irrelevant. In most of what follows, we suppose that lump-sum taxes and transfers are not included in the set of tax instruments. That is, the set of feasible tax policies is $\mathcal{T}$.

\section{Consumption taxes}

6.1 Example (Relevance of $\delta$ ): Consider a stationary overlapping-generations economy with one commodity per period $(\ell=1)$ and two consumers per generation $(n=2)$. The two consumers, Mr. $t 1$ and Mr. t2, have respectively the log-linear utility functions and endowments given by:

$$
\begin{aligned}
u_{t 1}\left(x_{t 1}^{t}, x_{t 1}^{t+1}\right) & =(1 / 3) \log x_{t 1}^{t}+(2 / 3) \log x_{t 1}^{t+1}, \\
\omega_{t 1} & =\left(\omega_{t 1}^{t}, \omega_{t 1}^{t+1}\right)=(1,1), \\
u_{t b}\left(x_{t 2}^{t}, x_{t 2}^{t+1}\right) & =(1 / 2) \log x_{t 2}^{t}+(1 / 2) \log x_{t 2}^{t+1},
\end{aligned}
$$

and 


$$
\omega_{t b}=\left(\omega_{t 2}^{t}, \omega_{t 2}^{t+1}\right)=(3,1) .
$$

For period $t$ we have from (6.2) the system of demand functions

$$
\begin{aligned}
x_{t-1,1}^{t}= & \frac{2\left(p^{t-1}+p^{t}\right)}{3 q_{t-1,1}^{t}}, \\
x_{t 1}^{t}= & \frac{p^{t}+p^{t+1}}{3 q_{t 1}^{t}}, \\
x_{t-1,2}^{t}= & \frac{3 p^{t-1}+p^{t}}{2 q_{t-1,2}^{t}}, \\
& \text { and } \\
x_{t 2}^{t}= & \frac{3 p^{t}+p^{t+1}}{2 q_{t 2}^{t}},
\end{aligned}
$$

where the $p$ 's are before-tax market prices and the $q$ 's are after-tax personalized prices. We assume that taxes must be completely anonymous within a given generation, i.e. we have $N=1$. There is only one commodity per period, i.e. we have $L=\ell=1$. Because of tax anonymity, we have

$$
\begin{aligned}
q_{t-1,1}^{t}= & q_{t-1,2}^{t}=q_{t-1}^{t}, \\
\tau_{t-1,1}^{t}= & \tau_{t-1,2}^{t}=\tau_{t-1}^{t}, \\
q_{t 1}^{t}= & q_{t 2}^{t}=q_{t}, \\
& \text { and } \\
\tau_{t 1}^{t}= & \tau_{t 2}^{t}=\tau_{t}^{t} .
\end{aligned}
$$

For convenience (and not more), we look at a steady state competitive equilibrium. The steady state allocations associated with the zero-interest-rate steady state are given by:

$$
x_{t 1}=\left(x_{t 1}^{t}, x_{t 1}^{t+1}\right)=(2 / 3,4 / 3)
$$




$$
x_{t 2}=\left(x_{t 2}^{t}, x_{t 2}^{t+1}\right)=(\mathscr{2}, 2)
$$

Can we use anonymous consumption taxes $\left(\tau_{t-1}^{t}, \tau_{t}^{t}\right)$ to meet the deficit requirement $\delta^{t}$ in period $t$ without disturbing the allocations implemented by (6.5) ? Such a tax scheme must satisfy for each $t,(t=1,2, \ldots)$ the following equations:

$$
\begin{aligned}
\frac{2\left(p^{t-1}+p^{t}\right)}{3\left(p^{t}+\tau_{t-1}^{t}\right)} & =\frac{4}{3}, \\
\frac{p^{t}+p^{t+1}}{3\left(p^{t}+\tau_{t}^{t}\right)} & =\frac{2}{3}, \\
\frac{3 p^{t-1}+p^{t}}{2\left(p^{t}+\tau_{t-1}^{t}\right)} & =2, \\
\frac{3 p^{t}+p^{t+1}}{2\left(p^{t}+\tau_{t}^{t}\right)} & =2, \\
\left({ }^{4 / 3}+2\right) \tau_{t-1}^{t}+\left({ }^{2} / 3+2\right) \tau_{t}^{t} & =-\delta^{t} .
\end{aligned}
$$

Clearly, the only possible solution to the first four equations of (6.6) is of the form $p^{t}=(\beta)^{t} p^{1}=(\beta)^{t}, \tau_{t}^{t}=(\beta)^{t} \tau^{0}$, and $\tau_{t-1}^{t}=(\beta)^{t} \tau^{1}$, where $\beta \in \mathbb{R}$ is the interest factor, $\tau^{0} \in \mathbb{R}$ is the present value of the tax rate on the young and $\tau^{1} \in \mathbb{R}$ is the present value of the tax rate on the old.

The first two equations in (6.6) yield $\tau^{0}=0$ and $\beta=1$. The second two equations yield $\tau^{1}=0$. The last equation in (6.6) states that the government revenue must be equal to $-\delta^{t}$. The government cannot implement the zero-interest-rate steady state allocation as a constitutional equilibrium unless $\delta^{t}=0$ for $t=1,2, \ldots$. Notice that in the above exercise, the government was not initially restricted to only stationary fiscal policies.

Example (6.1) indicates that budget irrelevance can fail in economies both (1) with only distortionary taxes and (2) without the power to completely individualize tax rates. In example (6.1), there is only one commodity per period, $l=L=1$. There are two consumers per period, $n=2$, but there is only one consumer tax class per period, $N=1$.

The next proposition provides a necessary condition for generic irrelevance of restrictions on the government budget deficits. Roughly speaking, the condition is that the number of instruments exceed the number of goals. This proposition and those that 
follow it hold only generically - i.e. for an open and dense set of economies. In this way, degenerate cases - such as those in which individual endowments are colinear - are excluded.

6.7 Proposition (A necessary condition for the irrelevance of $\delta$ ): Let $\mathrm{x}$ be an equilibrium allocation that can be implemented by the fiscal policy $\tau \in \mathcal{T}$ with government deficits $\delta=\left(\delta^{1}, . ., \delta^{t}, \ldots\right)$. If we have

$$
(\ell-1) N+n+1>L N+\ell
$$

then for almost all deficit sequences $\delta^{\prime}$ there is no fiscal policy $\tau^{\prime} \in T$ that implements the equilibrium allocation $x$ with government deficits $\delta^{\prime}=\left(\left(\delta^{1}\right)^{\prime}, \ldots,\left(\delta^{t}\right)^{\prime}, \ldots\right)$.

6.8 Remark Suppose that the government is unconstrained by commodity tax classes; i.e. we have $L=\ell$. Then Proposition 6.7 says that generically the deficit restriction does not matter if the inequality $\ell+N \geq n+1$ holds. In the case of a single consumer tax class, $N=1$, this reduces to the simple condition that the number of commodities be at least as great as the number of consumers, i.e. $\ell \geq n$ is satisfied.

Proof of Proposition (6.7): The demand function of $f_{t h}$ of consumer h from generation $t(t=1,2, \ldots)$ is homogenous of degree zero in the after-tax prices $q_{t h}=\left(q_{t h}^{t}, q_{t h}^{t+1}\right)$ and his wealth $w_{t h}=p^{t} \cdot \omega_{t}^{t}+p^{t+1} \cdot \omega_{t}^{t+1}$. Renormalize the arguments of the demand function $f_{t h}$ by dividing by $q_{t h}^{t, 1}$. The demand function $f_{t h}$ then defines a diffeomorphism between the consumption set and $\mathbb{R}_{++}^{\ell-1} \times \mathbb{R}_{++}^{\ell} \times \mathbb{R}_{++}$. Let $Q_{t h}=\left(Q_{t h}^{t}, Q_{t h}^{t+1}\right) \in \mathbb{R}_{++}^{\ell-1} \times \mathbb{R}_{++}^{\ell}$ and $W_{t h} \in \mathbb{R}_{++}$be the value of the renormalized arguments of $f_{t h}$ associated with the constitutional equilibrium $x$ that can be implemented with the budget deficit sequence $\delta=\left(\delta^{1}, . ., \delta^{t}, \ldots\right)$. The demands $f_{t h}$ remain constant as $\delta$ is changed to $\delta^{\prime}=\left(\left(\delta^{1}\right)^{\prime}, \ldots,\left(\delta^{t}\right)^{\prime}\right.$, $\ldots$ ) if and only if all the renormalized arguments of $f_{\text {th }}$ are unaffected. For each consumer in generation 1 or later there are $(2 \ell-1)$ conditions coming from the price ratios and one condition coming from his budget constraint. The constitutional restriction on the government budget deficit adds the restriction on government revenue:

$$
\sum_{h=1}^{h=n}\left(\tau_{t-1, h}^{t} \cdot f_{t-1, h}^{t}+\tau_{t h}^{t} \cdot f_{t h}^{t}\right)=-\delta^{t} .
$$

The relevant system of equations for period $t$ is then:

$$
\begin{aligned}
\frac{1}{q_{t h}^{t I}}\left(\widehat{p}^{t}+\widehat{\tau}_{t h}^{t}\right) & =Q_{t h}^{t} \text { for } h=1, \ldots, n, \\
\frac{1}{q_{t h}^{t I}}\left(p^{t+1}+\tau_{t h}^{t+1}\right) & =Q_{t h}^{t+1} \text { for } h=1, \ldots, n, \\
\frac{1}{q_{t h}^{t I}}\left(p^{t} \cdot \omega_{h t}^{t}+p^{t+1} \cdot \omega_{h t}^{t+1}\right) & =W_{h t} \text { for } h=1, \ldots, n,
\end{aligned}
$$

and 


$$
\sum_{h=1}^{h=n} \sum_{i=1}^{\ell}\left[\tau_{t h}^{t i} f_{t h}^{t i}\left(Q_{t h}^{t}, Q_{t h}^{t+1}, W_{t h}\right)+\tau_{t-1, h}^{t i} f_{t-1, h}^{t i}\left(Q_{t-1, h}^{t-1}, Q_{t-1, h}^{t}, W_{t-1, h}\right)\right]=-\delta^{t}
$$

where right hand sides $\left(Q_{t h}^{t}, Q_{t h}^{t-1}, W_{t h}\right.$, and $\left.\delta^{t}\right)$ are fixed and $\widehat{p}^{t} \in \mathbb{R}_{++}^{\ell-1}$ and $\widehat{\tau}_{t h}^{t} \in \mathbb{R}^{\ell-1}$ are respectively the vectors $p^{t}$ and $\tau_{t h}^{t}$ without the first coordinate $\left(p^{t 1} \in \mathbb{R}_{++}\right.$or $\left.\tau_{t h}^{t 1} \in \mathbb{R}\right)$. The first two lines in system (6.9) provide $(2 \ell-1) n$ restrictions on the prices, but because of the limited potency of the government only $(2 \ell-1) N$ of these restrictions are independent. Assume for the moment, that the $p^{t}$ and $\tau_{t h}^{t}(h=1, \ldots, n)$ are predetermined. (We will justify this assumption when we consider consumer 0 ) Multiplication of (6.9) by $q_{t h}^{t 1} \in R_{++}$ creates a linear system of equations in $2 L N+\ell$ unknowns, i.e. $2 L N$ independent tax rates, $\left(\tau_{t h}^{t}, \tau_{t h}^{t+1}\right)$, and $\ell$ prices.

Comparing the number of equations and unknowns suggests that a necessary condition for there to be a solution to the system (6.9) is that we have

$$
(2 \ell-1) N+n+1 \leq 2 L N+\ell .
$$

Of course, a full argument should include the ranks of the relevant matrices. In the Appendix, we show that provided the endowments of the individual consumers are not colinear, these rank conditions are indeed fulfilled.

To complete the argument, consumers from generation 0 must be considered. The individual demand $f_{t h} \in \mathbb{R}_{++}^{\ell}$ of a consumer $h$ of generation 0 has the form $f_{0 h}^{1}\left(q_{0 h}^{1}, w_{0 h}\right)$ with $w_{0 h}=p^{1} \cdot \omega^{1}+m_{0 h}^{1}$. from homogeneity and the diffeomorphism property, the individual demands are constant through a policy change if and only if the quantities $\mathbb{R}_{0 h}^{1} \in \mathbb{R}_{++}^{\ell-1}$ and $W_{o h} \in \mathbb{R}_{++}$defined by

$$
\begin{aligned}
\widehat{p}^{1}+\widehat{\tau}_{0 h}^{1}= & \left(1+\tau_{0 h}^{11}\right) R_{0 h}^{1} \\
& \text { and } \\
p^{1} \cdot \omega_{o h}^{1}+m_{o h}^{1} & =\left(1+\tau_{0 h}^{11}\right) W_{0 h}
\end{aligned}
$$

for $h=1, \ldots, n$. For each consumer in generation 0 , there are $(\ell-1)$ equations coming from the prices and 1 equation coming from income. (Of course, $p^{11}=1$ and $p^{m}=1$ are fixed.) Ignoring the redundant equations due to the limited potency of the government, the system consists then of $(\ell-1) N+n$ equations (the constraint on the government budget is not included at this stage). On the other hand there are $L N$ taxes and $\ell-1$ prices. Counting equations and unknowns, the necessary "counting condition" for existence of a solution is then $(\ell-1) N+n \leq L N+\ell-1$. (The more complete rank computations of the relevant matrices are provided in the Appendix.) Since we have $(\ell-1) N+n \leq L N+\ell-1$ 
and $L \leq 1$, it follows that $(2 \ell-1) N+n \leq 2 L N+\ell-1$ and hence the necessary condition for the theorem is fulfilled. (Note that if $L=\ell$ both conditions coincide.)

6.10 Remark Some Authors [see e.g. Kotlikoff (1993)] either explicitly or implicitly adopt a less stringent notion of the constitutional restrictions on budget deficits. For these authors, a restriction is placed on the deficit in each period except the first period (giving the government "one last chance.") As can readily be seen from the above proof, even the weaker version of the government budget deficit restrictions can be relevant.

6.11 Remark It is not assured that $q_{t h}^{s i}-\tau_{t h}^{s i}$ is positive, i.e. we could have for some $s$ $(s=1,2, \ldots)$ and some $i(i=1, \ldots, \ell)$ that $p^{s i}<0$. This would be consistent with the formal model, but is, of course, inconsistent with free disposal of endowments.

Hence, if we admit free disposal, the conditions in Proposition 6.9 are not sufficient for irrelevance of restrictions on the government budget deficit. The next example shows that there is a case for which the necessary condition is also sufficient and hence irrelevance of budget restrictions holds.

6.12 Example (Irrelevance of $\delta$ in an economy with one commodity and one consumer): Consider an overlapping-generations economy with one commodity per period and one consumer per generation, i.e., $l=L=1$ and $n=N=1$. Consumption of the commodity is taxed. The consumer is of the same type as consumer 1 in Example 6.1. Consider the steady-state sequence of before-tax prices $p=\left(p^{1}, \beta p^{1},(\beta)^{2} p^{1}, \ldots,(\beta)^{t-1} p^{1}\right.$, $\ldots$ ), where $p^{t}=(\beta)^{t-1} p^{1}$ for $t=1,2, \ldots$ for $\beta \in \mathbb{R}$. If markets clear, then we must have

$$
\frac{2\left(\beta^{t-1} p^{1}+\beta^{t} p^{1}\right)}{3\left(\beta^{t} p^{1}+\tau_{t-1}^{t}\right)}+\frac{\beta^{t} p^{1}+\beta^{t+1} p^{1}}{3\left(\beta^{t} p^{1}+\tau_{t}^{t}\right)}=2 .
$$

In the absence of taxes this equation can be written as

$$
(\beta-1)(\beta-2)=0
$$

The steady state allocations associated with $\beta=1$ and $\beta=2$ are respectively $\left(2 / 3,{ }^{4} / 3\right)$ and $(1,1)$. Consider the case in which the government policy leads to a stationary nonzero government budget deficit $\delta \in \mathbb{R}$. (In the sequel, we show that it can be obtained with a constant consumption tax scheme. Of course, this means that for the time being the transition from the no-tax situation to the tax situation is ignored.) Let $\tau_{t-1}^{t}=(\beta)^{t} \tau^{1}$ and $\tau_{t}^{t}=(\beta)^{t} \tau^{0}$. Then the equations for the first ("monetary") steady state are:

$$
\begin{aligned}
\frac{2(p+\beta p)}{3 \beta p+3 \beta \tau^{1}} & =\frac{4}{3}, \\
\frac{p+\beta p}{3 p+3 \tau^{0}} & =\frac{2}{3},
\end{aligned}
$$


and

$$
\frac{4 \tau^{1}}{3}+\frac{2 \tau^{0}}{3}=-\delta^{t}
$$

where for convenience $\delta^{t}$ is expressed in current units rather than in present units. Substituing in the above equation yields

$$
\begin{aligned}
\frac{1+\beta}{1+\tau^{0}} & =2, \\
& \text { and } \\
\frac{1+\beta}{\left[1-(3 \delta / 4)-\left(\tau^{0} / 2\right)\right] \beta} & =2 .
\end{aligned}
$$

The first equation above reduces to $\beta=2 \tau^{0}+1$ and then the second yields

$$
4\left(\tau^{0}\right)^{2}-(2-6 \delta) \tau^{0}+3 \delta=0
$$

The solutions to this equation are given by

$$
\tau^{0}=-\frac{3}{4} \delta+\frac{1}{4} \pm \frac{1}{4} \sqrt{(1-3 \delta)^{2}-12 \delta}
$$

The only economically meaningful solutions are those such that $\tau^{0}>-1$ and $\tau^{1}>-1$ and hence $-\frac{3}{4} \delta-\frac{1}{2} \tau^{0}>-1$. It is trivial to see that for $\delta$ small the relevant value of the tax is also small and the above conditions are fulfilled (for $\delta \rightarrow 0$ the other solution is $\tau^{0}=\frac{1}{2}$ corresponding to the "real" steady state with the interest factor $\left.\beta=2\right)$. Consider, for example, the case with $\delta=0.05$. Then $\tau^{0}=0.125, \tau^{1}=-0.1$ and the discount factor is $\beta=1.25$. Clearly, in the case of small surpluses $(-1<<\delta<0)$ a solution also exists and is such that $\tau^{0}>-1$ and $\tau^{1}>-1$.

One of the particularities of the above example is that it only deals with a stationary budget policy and does not treat the transition to the steady state. The next example allows for a non-stationary sequence of government deficit restrictions. This example also shows that the necessary condition in Proposition 6.7 is not sufficient.

6.13 Example (Relevance of $\delta$ in an economy with one commodity and one consumer): Consider the economy of example 6.12. Suppose that at time 1 a budget restriction is imposed on the government $\delta^{1}<0$ for period 1 while $\delta^{t}=0$ for $t=2,3 \ldots$ 
- The government wishes to change its fiscal policy without disturbing the steady-state allocation. It will begin by taxing the consumer of generation 1 at the rate $\tau_{1}^{1}>0$, while leaving the old consumer untaxed. In order to fulfill the budget restriction $\delta^{1}$ the tax should be such that $\frac{2}{3} \tau_{1}^{1}=-\delta^{1}$. Then $\tau_{1}^{1}=-\frac{3}{2} \delta^{1}$. The second-period price $p^{2}$ is obtained using the demand of the young of generation 1: $p^{2}=1-3 \delta^{1}$. The old age demand gives $\tau_{1}^{2}=\frac{3}{2} \delta^{1}$. In period 2 , the government has to fulfill $\delta^{2}=0$. Therefore we have $(2 / 3) \tau_{2}^{2}+4 / 3\left[\left({ }^{3} / 2\right) \delta^{1}\right]=0$ from which we get $\tau_{2}^{2}=-3 \delta^{1}$ and $p^{3}=p^{2}+2 \tau_{2}^{2}=1-9 \delta^{1}$. The same procedure can be repeated in general (for $t>1$ )

$$
\begin{aligned}
p^{t+1} & =p^{t}+2 \tau_{t}^{t}, \\
2 \tau_{t}^{t+1}+\tau_{t+1}^{t+1} & =0,
\end{aligned}
$$

and

$$
\tau_{t}^{t+1}=-\tau_{t}^{t}
$$

The first terms in the sequence of prices are $p^{4}=1-21 \delta^{1}, p^{5}=1-45 \delta^{1}$ and $p^{6}=$ $1-93 \delta^{1}$. The sequence is in fact defined by $p^{t+1}=p^{t}-3 \cdot 2^{t-1} \delta^{1}$. It is easily seen that for any $\delta^{1}>0$ the condition on the positiveness of prices is violated after a finite number of periods. Therefore the tax sequence described above eventually becomes infeasible (after a finite number of iterations). On the other hand, restrictions to a positive government deficit (surpluss) are always feasible in this example.

These examples illustrate the fact that the set of policies that give the same allocation as a given policy is usually not empty but that unfortunately this set is not easy to characterize, even as a neighborhood of the original policy. Indeed, typically there may not exist an open neighborhood in the supnorm topology of the original sequence of budgets such that all sequences in that neighborhood are feasible and are associated to the original allocation.

One way out is to weaken the notion of deficit restriction to one that applies only to a finite number of periods. In example (6.13), in the set of budget restrictions of finite length there is a neighborhood of the original restriction for which we have generic deficit irrelevance. Define $\delta(T)=\left(\delta^{1}, \delta^{2}, \ldots, \delta^{t}, \ldots, \delta^{T}\right)$ to be a deficit restriction of finite length. For a competitive equilibrium to be constitutionaly feasible the deficit in period $t$ must be $\delta^{t}$ if $t=1,2, \ldots, T$; for $t>T$, deficit is unrestricted ${ }^{3}$.

\footnotetext{
${ }^{3}$ In Balasko and Shell (1986), it is shown that every strictly balanced fiscal policy (one for which the public debt is forever retired by some date T) is bonafide. This is an approach to "getting rid" of the tails to infinite budget sequences. The approach taken here is to "ignore" restrictions on the tails of infinite budget sequences.
} 
In what follows, we consider a first T-period neighborhood, $D^{T}(\delta)$, of the deficit restriction sequence $\delta=\left(\delta^{1}, \delta^{2}, \ldots, \delta^{t}, \ldots, \delta^{T}, \ldots\right)$.

6.14 Proposition (A sufficient condition for irrelevance of $\delta$ ): Suppose that $L=1$. Let $x$ be a constitutional equilibrium allocation that can be implemented by the fiscal policy $\tau \in \mathcal{T}$ with deficits $\delta$. Assume $\ell+N \geq n+1$. Then for almost all such $\delta$ there exists an open neighborhood $D^{T}(\delta)$ of $\delta$ (over $T$ periods), such that for all $\delta^{\prime} \in D^{T}(\delta)$ there is a fiscal policy $\tau^{\prime}$ that implements the allocation $x$.

Proof: The same rank conditions of the relevant matrices used in the proof of Proposition 6.7 and proved in the Appendix show that the set of solutions is nonempty as $\ell+N \geq n+1$.

To conclude this section: we have shown that, when the only instruments are consumption taxes, an exogenously given sequence of government budget restrictions can be fulfilled without changing the equilibrium allocation, but that this requires that there is a sufficiently rich spectrum of different tax instruments. Furthermore, the necessary condition for irrelevance cannot be turned into a global sufficiency result. For sufficiency, we need to be close to the comparison deficits and unrestricted in the tail of the deficit sequence.

Note that the effective impact of deficit restrictions on social welfare depends on the precise specification of the welfare function. However, one expects that social welfare based on individual utilities will be generally reduced by budget deficit restrictions. Thus budget specifications have, in this case, a real effect on the economy.

\section{Credit Restrictions}

In the present section, we consider the relevance of government deficit restrictions when at least some consumers face borrowing restrictions. These restrictions typically take the form of a maximal amount of loan an individual can obtain, so that it is likely that in equilibrium some consumers will find the borrowing constraints are binding.

Let $b_{t h}^{s} \in \mathbb{R}$ be the credit restriction in period $s$ on consumer $h$ from generation $t$. The problem for consumer th is then 


$$
\begin{aligned}
\operatorname{maximize} u_{h t}\left(x_{t h}^{t}, x_{t h}^{t+1}\right) & \\
\text { subject to } & \\
q_{t h}^{t} \cdot x_{t h}^{t}+x_{t h}^{t m} & =p^{t} \cdot \omega_{t h}^{t}+m_{t h}^{t}, \\
q_{t h}^{t+1} \cdot x_{t h}^{t+1}+x_{t h}^{t+1, m} & =p^{t+1} \cdot \omega_{t h}^{t+1}+m_{t h}^{t+1}, \\
x_{t h}^{t m} & \geq p^{t 1} b_{t h}^{t}, \\
\text { and } & \\
x_{t h}^{t m}+x_{t h}^{t+1, m} & =0,
\end{aligned}
$$

where $x_{t h}^{s m} \in \mathbb{R}$ is the gross money holding in period $s$ by consumer $h$ of generation $t$. If $x_{t h}^{s m}$ is negative, the consumer is borrowing in period $s$. The last equation in (7.1) is the requirement that the consumer's indebtedness be zero in his latest period of life. The inequality in (7.1) is the restriction of credit. In the system (7.1) it is implicitly assumed that the borrowing of at least one consumer is unrestricted; hence we can set $p^{t m}=p^{t+1, m}=p^{m}$. Assuming that the economy is in proper monetary equilibrium, we can without loss of generality set $p^{m}=1$. The inequality in (7.1) puts the credit restrictions in real terms rather than nominal terms. In the latter case, the constraint would have been $x_{t h}^{t m} \geq b_{t h}^{t}$, assuming that the present price of money is set to unity. If there are more than one commodity per period $(\ell>1)$, then a choice of price index is required in the inequality in (7.1). We have chosen for simplicity to put the entire weight on the current price of the first commodity. If the credit restriction were based on another price index or stated in nominal (money) units, our results would not be affected.

The next result provides the conditions for the irrelevance of restrictions on government deficit in economies with restrictions on consumer credit and lump-sum transfers.

Proposition 7.2 (Relevance of deficit restrictions with borrowing-contrained consumers): Suppose that there is at least one consumer whose credit restriction is not binding. Let the allocation $x$ be implemented as a constitutional competitive equilibrium with the fiscal policy $m \in \mathcal{M}$ consisting only of lump-sum transfers, with the deficit restriction $\delta$. If the government is able to "identify" the unrestricted consumer, then for any deficit sequence $\delta$ there is a fiscal policy $m \in \mathcal{M}$ that implements the allocation $x$ as a constitutional competitive equilibrium. Otherwise, restrictions on the government budget deficit can matter.

Proof: If the government can identify an unrestricted consumer, then renumber the consumers so that consumer 1 is this consumer. Then the proof is the same as for Proposition 5.1. If the government is unable to identify an unrestricted consumer, the procedure in the proof of Proposition 5.1 fails, since a transfer may change the status 
of some consumer in respect to whether or not he is restricted and therefore change his demand for commodities.

Proposition 7.2 implies that fixing the government deficit sequence does not restrict the set of implementable allocations that can be obtained with lump-sum transfers as long as the government is able to individualize the transfer to some unrestricted consumer. Identifying an unrestricted consumer is not always a realistic possibility. This is illustrated in the following example.

7.3 Example (Relevance of $\delta$ in an 3-person economy with restrictions on consumer's credit): Let the economy be stationary with one commodity per period and three consumers. Perfectly anonymous lump-sum taxes and transfers are available. The three consumers, noted as 1, 2, and 3, are characterized by the log-linear utility functions

$$
u_{t h}=1 / 2 \log x_{t h}^{t}+1 / 2 \log x_{t h}^{t+1}
$$

for $h=1,2,3$ and $t=1,2, \ldots$. Endowments are given

$$
\begin{aligned}
\omega_{t 1}= & \left(\omega_{t 1}^{t}, \omega_{t 1}^{t+1}\right)=(1,1), \\
\omega_{t 2}= & \left(\omega_{t 2}^{t}, \omega_{t 2}^{t+1}\right)=(1,5), \\
& \text { and } \\
\omega_{t 3}= & \left(\omega_{t 3}^{t}, \omega_{t 3}^{t+1}\right)=(2,1) .
\end{aligned}
$$

Consider date $t$. Let the deficit specification be $\delta^{t}=0$. Suppose the borrowing of consumer 1 is unrestricted but that consumers of types 2 and 3 cannot borrow $b_{t 2}^{t}=0$ and $b_{t 3}^{t}=0$. Then $(p, \beta)=(1,1)$ represents a steady state equilibrium price system. The corresponding equilibrium allocations are

$$
\begin{aligned}
x_{t 1}= & \left(x_{t 1}^{t}, x_{t 1}^{t+1}\right)=(1,1), \\
x_{t 2}= & \left(x_{t 2}^{t}, x_{t 2}^{t+1}\right)=(1,5), \\
& \text { and } \\
x_{t 3}= & \left(x_{t 3}^{t}, x_{t 3}^{t+1}\right)=(3 / 2,3 / 2) .
\end{aligned}
$$


Suppose now that the government is required to run a surplus in every period with $\delta^{t}=-30$ for $t=1,2, \ldots$.

It is easy to see that the new restriction on the deficits must lead to a modification of the existing allocation. The government can either transfer to the young or to the old. Suppose it transfers to the young. The procedure is similar to that used in the proof of Proposition 5.1. Suppose, since the consumers of the same generation are perfectly anonymous, that we give each of them ten units in lump-sum taxes, e.g.. we have $m_{t 1}^{t}$ $=m_{t 2}^{t}=m_{t 3}^{t}=10$. Suppose that we tax each of the old ten units, i.e. $m_{t-1,1}^{t}=m_{t-1,2}^{t}=$ $m_{t-1,3}^{t}=-10$. Consumers of type 2 will have substantial liquidity when young and will not have a need to borrow. Hence we have $x_{t 2}=(3,3)$ : the equilibrium allocation $x$ has been altered. By taxing the young so that $m_{t 1}^{t}=m_{t 2}^{t}=m_{t 3}^{t}<0$, the allocation will be affected by the increased liquidity constraints on the restricted consumers. Hence the allocation $\mathrm{x}$ which was supportable as a constitutional equilibrium with $\delta^{t}=0$ for $t=1,2, \ldots$, is not supportable as a constitutional equilibrium with $\left(\delta^{t}\right)^{\prime}=-30$ for $t=1,2, \ldots$

When only taxes on consumption are available, the conditions for irrelevance of deficit restrictions rests on the difference between the number of tax instruments and the number of consumers. The next proposition is based on the economy in which only perfectly anonymous consumption taxes are available to the government. A typical situation is one in which some consumers are restricted by the credit rationing while others not. Besides the conditions that apply when rationing is absent, a new set of inequalities must be satisfied for deficits to be irrelevant. Clearly a sufficient condition is that the real borrowings and lendings be unaltered by a change in $\delta$.

7.4 Proposition (Relevance of $\delta$ in economies with consumption taxes and consumer borrowing restrictions): Suppose that only anonymous consumption taxes are available and that the credit of at least one consumer is not restricted. Let $x$ be an allocation that can be implemented as a constitutional equilibrium with an (anonymous) fiscal policy $\tau \in \mathcal{T}$ and deficit restriction $\delta$. Then, if $n \leq \ell / \mathscr{2}$ for any deficit restriction satisfying the conditions of Proposition 6.14, there is a fiscal policy $\tau^{\prime} \in \mathcal{T}$ that implements the equilibrium allocation $x$. In the case $\ell / \mathscr{2}<n \leq \ell$, such a policy $\tau^{\prime} \in T$ may or may not exist, while for $\ell<n$, it simply fails to exist.

Proof: When consumers are potentially restricted, demand for commodities may depend on the individual borrowings or lendings, so that these must be kept constant when the policy changes. Formally, $x_{t h}^{t m} / p^{t 1}$, with $x_{t h}^{t m}=p^{t} \cdot \omega_{t h}^{t}-q_{t h}^{t} \cdot x_{t h}^{t}$, is kept constant for constrained consumers. Denote this quantity by $\bar{b}_{t h}^{t}$. Furthermore, since there is an unconstrained consumer, prices in successive periods are linked. Therefore, in period $t$ the relevant system consists of $2 \ell-1$ conditions on prices and $2 n$ conditions on individual wealth. Taking into account the restriction on the deficit, the system of $2 \ell+2 n$ equations 
can be written as

$$
\begin{aligned}
\widehat{p}^{t}+\widehat{\tau}_{t}^{t} & =\left(p^{t 1}+\tau_{t}^{t 1}\right) R_{t}^{t}, \\
p^{t+1}+\tau_{t}^{t+1} & =\left(p^{t 1}+\tau_{t}^{t 1}\right) R_{t}^{t+1}, \\
p^{t} \cdot \omega_{t h}^{t}-p^{t 1} \bar{b}_{t h}^{t} & =\left(p^{t 1}+\tau_{t}^{t 1}\right) W_{t, h}^{t}, \\
p^{t} \cdot \omega_{t h}^{t}+p^{t+1} \cdot \omega_{t h}^{t+1} & =\left(p^{t 1}+\tau_{t}^{t 1}\right) W_{t h},
\end{aligned}
$$

and

$$
\sum_{h=1}^{h=n} \sum_{i=1}^{i=\ell} \tau_{t}^{t i} f_{t h}^{t i}\left(R_{t}^{t}, R_{t}^{t+1}, W_{t h}\right)+\tau_{t-1}^{t, i} f_{t-1, h}^{t, i}\left(R_{t-1}^{t-1}, R_{t-1}^{t}, W_{t-1, h}\right)=-\delta^{t},
$$

for $i=1, \ldots, \ell$, where the $R$ 's, the $W$ 's, and the $\delta$ 's are fixed. Remark that due to the first and second set of equations, the constraints on $x_{t h}^{t m}$ do not involve the allocations. Note also that here individual demands for a constrained consumer may depend only trivially on some of the arguments specified above.

Suppose that $n \leq \ell$. In the Appendix, it is shown that it is useful to consider as "free" variables the last $\ell-n$ prices of period $t: p^{t, n+1}, \ldots, p^{t \ell}$ and the first $n$ prices of period $t+1: p^{t+1,1}, \ldots, p^{t+1, n}$. This system, which is linear in $3 \ell$ unknowns, has a solution if and only if $n \leq \ell / 2$. The usual sign restrictions on the $p$ 's applies so this condition is not sufficient. The second part of the proposition is true because of the fact that the policy change may not alter the distribution of restricted consumers. .

7.5 Remark: The general case of individualized taxes can be deduced from Proposition 7.4. Also note that irrelevance breaks down even if the first period deficit is unrestricted.

An interesting question concerns the possibility that the government might be able to provide enough individual liquidity to "free" each consumer from his credit restriction. This would be an action that could improve social welfare. Consider then an economy in which some of the consumers are not able to borrow as they would like to. A seemingly attractive fiscal policy would be to proceed to a sufficiently large lump-sum transfer to the consumers in their youth and an equally large tax in their old age. Does the feasibility of such a policy depend on the deficit restrictions imposed on the government?

The conditions for making each consumer liquid are in fact identical to those for the irrelevance of the deficit restrictions. Indeed, when a "free consumer" can be found, a liquidity possibility can be obtained in a fashion similar to that for Proposition 7.4. When no free consumer can be identified and/or only anonymous lump-sum transfers are used, the irrelevance result can be obtained only if the specification does not concern the 
first period of the economy (or, the first period of the economic plan). This is because, when individuals cannot be differentiated, large initial transfers to the young restricted consumers have to be balanced by an equally large tax on the old consumers, an action which has serious welfare consequences in the first period. When consumption taxes are applied, no clear result can be obtained, since the existence of the full-liquidity scheme is only established for a subset of the set of deficit sequences (see Proposition 6.14).

\section{Concluding remarks}

We hope we have shed some light on a puzzle about restrictions on the government's budget deficit. Politicians seem to be convinced that such restrictions matter a lot (perhaps for good, perhaps for ill). The existing theoretical literature suggests that these restrictions don't matter.

We go beyond the simple economies with only lump-sum taxation or only one consumer per generation or only one commodity per generation. We show that deficit irrelevance requires an unrealistically large number of independent policy tools. Even with these tools, deficit irrelevance is far from guaranteed. If large changes in deficit are required then deficit restrictions may be relevant. If restrictions are imposed on the full infinite path of deficits, then these restrictions might matter - in fact, they could well be inconsistent with any equilibrium.

The budget deficit is typically a complicated function of the tax rate and the equilibrium allocation (which itself depends on the tax rates). Because of the possibility of multiple equilibria, the deficit is not a single-valued function of the tax rates. This is what makes the analysis complicated.

We assume perfect foresight and once-and-for-all perfect commitement by the consumers and government. In the case of the government, this is an heroic assumption.

There is one very important caveat: The notion in this paper of "deficit restriction irrelevance" (or, "restriction on the government budget deficit do not matter") could be misleading. We study here the class of all rational expectations equilibria. Particular rational-expectations equlibria might be conditioned on observed or projected budget deficits.

\section{References}

Alesina, A., and R. Perotti, 1996, Budget Deficits and Budget Institutions, NBER Working Paper 5556.

Auerbach, A.J., and L. J. Kotlikoff, 1987, Dynamic Fiscal Policy, Cambridge University Press. 
Balasko, Y., 1988, Foundations of the theory of general equilibrium, Academic Press, Boston, MA.

Balasko, Y., and K. Shell, 1980, The Overlapping-Generations Model, I: the case of pure exchange without money, Journal of Economic Theory, 23, 281-306.

Balasko, Y., and K. Shell, 1981, The Overlapping-Generations Model, II: the case of pure exchange with money, Journal of Economic Theory, 24, 112-142.

Balasko, Y., and K. Shell, 1986, Lump sum taxes and transfers: public debt in the overlapping generation model, in Equilibrium analysis: Essays in honor of Kenneth J. Arrow, Volume II,

Balasko, Y., and K. Shell, 1993, Lump sum taxation: the static economy, in General Equilibrium, Growth and Trade II, Essays in Honor of Lionel McKenzie, Academic Press.

Bohn, H., and R. Inman, 1996, Balanced Budget Rules and Public Deficits: Evidence from the U.S. States, NBER Working Paper 5533.

Diamond, P. A., and J.A. Mirrlees, 1971, Optimal Taxation and Public Production I-II, American Economic Review, 61, 8-27, 261-278.

Heller, W. P., and K. Shell, 1974, On Optimal Taxation with Costly Administration, American Economic Review, Papers and Proceedings, 64, 338-345.

Kelly, M. A., 1991, Does Gramm-Rudman Matter?, CAE Working Paper 91-19, Cornell University

Kotlikoff, L. J., 1993, From Deficit Delusion to the Fiscal Balance Rule, Journal of Economics, Suppl. 7, 17-41.

Mirrlees, J. A., 1976, Optimal Taxation Theory: A Synthesis, Journal of Public Economics, 6, 327-358.

Mitra, T., 1987, Public Dept in The Overlapping Generations Model: A Characterization of Bonafide Tax-Transfer Policies, CARESS Working paper 87-04, University of Pennsylvania.

Poterba, J., 1996, Do Budget Rules Work?, NBER Working Paper 5550.

Samuelson, P. A., 1958, An Exact Consumption-Loan Model of Interest with or without the Social Contrivance of Money, Journal of Political Economy, 66, 467-482.

\section{Appendix: Rank computations}

\section{Consumption taxes}

In order to obtain the relevant rank conditions we will consider the two polar cases.

Individualized taxes. Here we suppose that $N=n$ and $L=l$, i.e. the government can perfectly distinguish the consumers and is able to apply a different tax rate to every 
commodity. For a consumer $h$ of generation $t=1,2, \ldots$, the relevant linear system can be written in matrix form

$$
A_{t} z_{t}=\left[\begin{array}{cccc}
0 & -Q_{t}^{t} & I_{n(l-1)} & 0 \\
\bar{J}_{l n} & -Q_{t}^{t+1} & 0 & I_{n l} \\
\omega_{t}^{t+1} & -W_{t} & 0 & 0 \\
0 & f_{t}^{t 1} & \hat{f}_{t}^{t} & 0
\end{array}\right]\left[\begin{array}{c}
p^{t+1} \\
\tau_{t}^{t 1} \\
\hat{\tau}_{t}^{t} \\
\tau_{t}^{t+1}
\end{array}\right]=\left[\begin{array}{c}
-P_{t}+p^{t 1} Q_{t}^{t} \cdot J_{n} \\
p^{t 1} Q_{t}^{t+1} \cdot J_{n} \\
-\omega_{t}^{t} P_{t}+p^{t 1} W_{t} \cdot J_{n} \\
\delta^{t}-\sum_{h=1}^{n} \sum_{i=1}^{l} \tau_{t-1 h}^{t i} f_{t-1, h}^{t i}
\end{array}\right]
$$

where the matrices $Q_{t}^{s}, \bar{J}_{l n}, \omega_{t}$ and $W_{t}$ and the vectors $J_{n}, P_{t}, \tau_{t}^{s}$ and $\omega_{t}^{t}$ are defined by

$$
\begin{aligned}
& Q_{t}^{s}=\left[\begin{array}{cccc}
Q_{t 1}^{s} & 0 & \ldots & 0 \\
0 & Q_{t 2}^{s} & \ldots & 0 \\
\vdots & \vdots & \vdots & \vdots \\
0 & 0 & \ldots & Q_{t n}^{s}
\end{array}\right], Q_{t h}^{t} \in \mathbb{R}^{l-1} \text { and } Q_{t h}^{t+1} \in \mathbb{R}^{l} \\
& \bar{J}_{l n}=\left[\begin{array}{c}
I_{l} \\
I_{l} \\
\vdots \\
I_{l}
\end{array}\right]_{l n \times l}, J_{n}=\left[\begin{array}{c}
1 \\
1 \\
\vdots \\
1
\end{array}\right]_{n \times 1}, P_{t}=\left[\begin{array}{c}
p^{t} \\
p^{t} \\
\vdots \\
p^{t}
\end{array}\right]_{l n \times 1}, \tau_{t}^{s}=\left[\begin{array}{c}
\tau_{t 1}^{s} \\
\tau_{t 2}^{s} \\
\vdots \\
\tau_{t n}^{s}
\end{array}\right]_{l n \times 1} \\
& \omega_{t}^{t+1}=\left[\begin{array}{cccc}
\omega_{t 1}^{t+1,1}, & \omega_{t 1}^{t+1,2} & \ldots, & \omega_{t 1}^{t+1, l} \\
\omega_{t 2}^{t+1,1}, & \omega_{t 2}^{t+1,2} & \ldots, & \omega_{t 2}^{t+1, l} \\
\vdots & \vdots & \vdots & \vdots \\
\omega_{t n}^{t+1,1}, & \omega_{t n}^{t+1,2} & \ldots, & \omega_{t n}^{t+1, l}
\end{array}\right]_{n \times l}, \omega_{t}^{t^{\prime}}=\left[\begin{array}{c}
\omega_{t 1}^{t} \\
\omega_{t 2}^{t} \\
\vdots \\
\omega_{t n}^{t}
\end{array}\right]_{l n \times 1}, \\
& \text { and } W(t)=\left[\begin{array}{cccc}
w_{t 1} & 0 & \ldots & 0 \\
0 & w_{t 2} & \ldots & 0 \\
\vdots & \vdots & \vdots & \vdots \\
0 & 0 & \ldots & w_{t n}
\end{array}\right]_{n \times n}
\end{aligned}
$$

The notation for the individual demands is given by

$$
\begin{gathered}
f_{t}^{t 1}=\left(f_{t h}^{t 1}\left(Q_{t h}^{t}, Q_{t h}^{t+1}, w_{t h}\right)\right)_{h=1}^{n}, \\
\hat{f}_{t}^{t}=\left(f_{t h}^{t i}\left(Q_{t h}^{t}, Q_{t h}^{t+1, i}, w_{t h}\right)\right)_{h=1, \ldots, n}^{i=2, \ldots, l},
\end{gathered}
$$

and

$$
f_{t}^{t+1}=\left(f_{t h}^{t+1}\left(Q_{t h}^{t}, Q_{t h}^{t+1}, w_{t h}\right)\right)_{h=1, \ldots, n}^{i=1, \ldots, l}
$$


Similar notation appears for taxes $\tau_{t}^{t 1}, \hat{\tau_{t}^{t}}$ and $\tau_{t}^{t+1}$.

The rank of the matrix $A_{t}$ is equal to the rank of the matrix

$$
\left[\begin{array}{ccc}
0 & -Q_{t}^{t} & I_{n(l-1)} \\
\omega_{t}^{t+1} & -W_{t} & 0 \\
0 & f_{t}^{t 1} & \hat{f}_{t}^{t}
\end{array}\right]
$$

plus $l n$. By a sequence of manipulations involving the first $n(l-1)$ rows of this last matrix, the rank of the $A_{t}$ matrix is seen to be equal to the rank of the $n+1 \times n+l$ matrix

$$
M=\left[\begin{array}{cc}
0 & \Sigma(t) \\
\omega_{t}^{t+1} & -W_{t}
\end{array}\right]_{n+1 \times n+l}
$$

plus $2 n l-n$ where $\Sigma(t)$ is given by

$$
\Sigma(t)=\left(\sum_{i=2}^{l} f_{t 1}^{t i} Q_{t 1}^{t i}+f_{t 1}^{t 1}, \ldots, \sum_{i=2}^{l} f_{t n}^{t i} Q_{t n}^{t i}+f_{t n}^{t 1}\right) .
$$

Note that, since the coordinates of $\Sigma(t)$ represent the first period wealth of the consumers, we generally have $\Sigma(t) \in(\mathbb{R} \backslash\{0\})^{n}$.

Suppose that $n \leq l$, then the matrix $M_{t}$ has rank $n+1$ when $\omega_{t}^{t+1}$ has maximal rank, a generical property for non-colinear endowments. In this case, the matrix $A_{t}$ has rank $2 n l+1$ and the set of solution of $A_{t} x_{t}=b_{t}$ is nonempty.

If $n>l$, let $p=n-l$ so that the rank of the matrix $M$ is equal to $p+1$ plus the rank of the square matrix

$$
\left[\begin{array}{cccc}
\omega_{t 1}^{t+1,1} & \omega_{t 1}^{t+1,2} & \ldots & \omega_{t 1}^{t+1, l} \\
\omega_{t 2}^{t+1,1} & \omega_{t 2}^{t+1,2} & \ldots & \omega_{t 2}^{t+1, l} \\
\vdots & \vdots & \vdots & \vdots \\
\omega_{t, n-p-1}^{t+1} & \omega_{t, n-p-1}^{t+1,2} & \ldots & \omega_{t, n-p-1}^{t+1, l} \\
-{ }_{n-p t}^{11} & -{ }_{n-p t} & \ldots & -{ }_{n-p t}{ }_{n-p t}
\end{array}\right]_{l \times l}
$$

with $-{ }_{n-p t}^{1 i}=\Sigma_{n}^{-1} w_{n} \sum_{s=0}^{n-p} \omega_{n-s t}^{n-s t, i}\left(w_{n-s}^{-1} \Sigma_{n-s}\right)$. The rank of this last matrix can be seen to be maximal for an open and dense set of endowments. Hence the matrix $M_{t}$ has rank $n-l+1+l=n+1$ and the set of solutions of $A_{t} x_{t}=b_{t}$ is also nonempty.

Anonymous consumption taxes. Here we suppose that $N=1$ and $L=l$, i.e. the government cannot discriminate any of the consumers in a given generation but is able to use a different tax for each commodity. The extension to the case $L<l$ is straightforward.

The linear system associated to a consumer of generation 0 can be written as $A_{1} z_{1}=b_{1}$ or 


$$
\left[\begin{array}{ccc}
I_{l-1} & -R_{0}^{1} & I_{l-1} \\
& -W_{1} & 0 \\
\hat{\omega}_{0}^{1} & \vdots & \\
& -W_{n} & 0
\end{array}\right]_{l+n-1 \times 2 l}\left[\begin{array}{c}
\hat{p}^{1} \\
\tau_{1}^{11} \\
\hat{\tau}_{1}^{1}
\end{array}\right]_{2 l-1 \times 1}=\left[\begin{array}{c}
R_{0}^{1} \\
W_{1}-\omega_{01}^{11}-m_{01}^{1} \\
\vdots \\
W_{n}-\omega_{0 n}^{11}-m_{0 n}^{1}
\end{array}\right]_{l+n-1 \times 1}
$$

with

$$
\hat{\omega}_{t}^{t+1}=\left[\begin{array}{cccc}
\omega_{t 1}^{t+1,2} & \omega_{t 1}^{t+1,3} & \ldots & \omega_{t 1}^{t+1, l} t+1 \\
\omega_{t 2}^{2}(t+1) & \omega_{t 2}^{t+1,3} & \ldots & \omega_{t 2}^{t+1, l} \\
\vdots & \vdots & \vdots & \vdots \\
\omega_{t n}^{2}(t+1) & \omega_{t n}^{t+1,3} & \ldots & \omega_{t n}^{t+1, l}
\end{array}\right]_{n \times l-1}
$$

The rank of the matrix $A_{1}$ is equal to the rank of the matrix

$$
\left[\begin{array}{ccc} 
& & -W_{1} \\
\hat{\omega}_{0}^{1} & \vdots & \\
& & -W_{n}
\end{array}\right]_{n \times l+1}
$$

plus $l-1$. It is trivial to prove that the above matrix has maximal rank. Therefore, the matrix $A$ has rank $l-1+\min (n, l+1)$ while there are $2 l$ unknowns. For $n=l$ there are $2 l$ equations, therefore a solution always exists although the dimension of the solution set is zero. The unknowns $p^{t}$ and $\tau_{t-1}^{t}$ are determined, independently of any budget specification. This remark holds also in the case with $n>l$ since then new equations are added to the system while no new unknown is considered.

Consider now the consumers of generation $t \geq 1$, with the constraint that the price in period $t$ is already fixed. In matrix form, the relevant system of equations that include the budget restriction can be written as $A_{t} z_{t}=b_{t}$ or

$$
\left[\begin{array}{cccc}
0 & -R_{t}^{t} & I_{l-1} & 0 \\
I_{l} & -R_{t}^{t+1} & 0 & I_{l} \\
\omega_{t}^{t+1} & -W_{t} \cdot J_{n} & 0 & 0 \\
0 & \sum_{h=1}^{n} f_{t h}^{t 1} & \sum_{h=1}^{n} \hat{f}_{t h}^{t} & 0
\end{array}\right]\left[\begin{array}{c}
p^{t+1} \\
\tau_{t}^{t 1} \\
\hat{\tau}_{t}^{t} \\
\tau_{t}^{t+1}
\end{array}\right]=\left[\begin{array}{c}
-\hat{p}^{t}+p^{t 1} R_{t}^{t} \\
p^{t 1} R_{t}^{t+1} \\
-\omega_{t}^{t} P_{t}+p^{t 1} W_{t} \cdot J_{n} \\
\delta^{t}-\sum_{h=1}^{n} \sum_{i=1}^{l} \tau_{t-1}^{t i} f_{t-1, h}^{t i}
\end{array}\right]
$$

where the individual demands are denoted by $f_{t h}^{t 1}=f_{t h}^{t 1}\left(R_{t}^{t}, R_{t}^{t+1}, W_{t h}\right), \hat{f_{t h}^{t}}=$ $\left(f_{t h}^{t i}\left(R_{t}^{t}, R_{t}^{t+1}, W_{t h}\right)\right)_{i=2, \ldots, l}$ and $f_{t h}^{t+1}=\left(f_{t h}^{t+1, i}\left(R_{t}^{t}, R_{t}^{t+1}, W_{t h}\right)\right)_{i=1, \ldots, l}$. The taxes $\sigma_{t}^{t 1}, \hat{\sigma}_{t}^{t}$ and $\sigma_{t-1}^{t}$ follows the same notation.

The rank of the matrix $A_{t}$ is equal to the rank of the matrix 


$$
\left[\begin{array}{ccc}
0 & -R_{t}^{t} & I_{l-1} \\
\omega_{t}^{t+1} & -W_{t} \cdot J_{n} & 0 \\
0 & \sum_{h=1}^{n} f_{t h}^{t 1} & \sum_{h=1}^{n} \hat{f_{t h}^{t}}
\end{array}\right]
$$

plus $l$. By a sequence of manipulations involving the first $l-1$ raws of this last matrix, the rank of the matrix $A_{t}$ is seen to be equal to the rank of the $n+1 \times l+1$ matrix

$$
\left[\begin{array}{cc}
0 & \Sigma(t) \\
\omega_{t} & -W(t) \cdot J_{n}
\end{array}\right]
$$

plus $2 l-1$ where $\Sigma(t)=\sum_{h=1}^{n} \sum_{i=2}^{l} f_{t h}^{t i} R_{t}^{t i}+\sum_{h=1}^{n} f_{t h}^{t 1}$. Each of the terms of the sum over of consumers in $\Sigma(t)$ represent the first period wealth of the consumers, therefore generically $\Sigma(t)$ will not be zero. Then the matrix $A_{t}$ has maximal rank if the matrix $\omega$ has maximal rank, which follows if the initial endowments are not colinear. The rank of the matrix $A$ is then $\min (2 l+n, 3 l)$.

The system has no solution if $\operatorname{Rank}\left(A_{t}\right)<\operatorname{Rank}\left(A_{t}, b_{t}\right)$. The rank of the augmented matrix is equal to the rank of the matrix

$$
\left[\begin{array}{cccc}
0 & -R_{t}^{t} & I_{l-1} & -p^{t}+p^{t 1} R_{t}^{t} \\
\omega_{t}^{t+1} & -W_{t} \cdot J_{n} & 0 & -\omega_{t}^{t} P_{t}+p^{t 1} W_{t} \cdot J_{n} \\
0 & \sum_{h=1}^{n} f_{t h}^{t 1} & \sum_{h=1}^{n} \hat{f}_{t h}^{t} & \delta^{t}-\sum_{h=1}^{n} \sum_{i=1}^{l} \tau_{t-1}^{t i} f_{t-1, h}^{t i}
\end{array}\right]_{n+l \times 2 l+1}
$$

plus $l$. If $n=l+1$ this is a square matrix. It has full rank $2 l+1$ for an open and dense set of values of $\delta^{t}$ provided that the coefficient of $\delta^{t}$ in the polynomial expression representing the determinant of $\left(A_{t}, b_{t}\right)$ is nonzero. Since this coefficient is the determinant of

$$
\left[\begin{array}{ccc}
0 & -R_{t}^{t} & I_{l-1} \\
\omega_{t}^{t+1} & -W_{t} \cdot J_{n} & 0
\end{array}\right]_{2 l \times 2 l}
$$

the relevant condition is that the determinant of

$$
\left[\begin{array}{ll}
\omega_{t}^{t+1} & -W_{t} \cdot J_{n}
\end{array}\right]=\left[\begin{array}{ccccc}
\omega_{t-1,1}^{t 1}, & \omega_{t-1,1}^{t 2}, & \ldots, & \omega_{t-1,1}^{t l} & -W_{t 1} \\
\omega_{t-1,2}^{t 1}, & \omega_{t-1,2}^{t 2}, & \ldots, & \omega_{t-1,2}^{t l} & -W_{t 2} \\
\vdots & \vdots & \vdots & \vdots & \vdots \\
\omega_{t-1, n}^{t 1}, & \omega_{t-1, n}^{t 2}, & \ldots, & \omega_{t-1, n}^{t l} & -W_{t n}
\end{array}\right]_{l+1 \times l+1}
$$

is nonzero. This determinant is generically nonzero because $W_{h}$ involves both $\omega_{t h}^{t}$ and $\omega_{t h}^{t+1}$. Therefore, for a dense and open set of budget specifications when $n=l+1$, $\operatorname{Rank}\left(A_{t}\right)=3 l<3 l+1=\operatorname{Rank}\left(A_{t}, b_{t}\right)$, i.e. the system has no solution. Of course this is the knife edge case. For $n \leq l, \operatorname{Rank}\left(A_{t}\right)=\operatorname{Rank}\left(A_{t}, b_{t}\right)$ and the system has a solution, while for $n \geq l+1$ there is no solution. 


\section{Credit restrictions and consumption taxes}

For notational convenience, we focus attention on the case $n \geq 2$. First, consider a consumer of generation 0 . It is clear from the last section, that the set of free parameters left after imposing the condition of constant individual demands to these consumers is a set of dimension $l-n$. Let us then consider as free the last $l-n$ prices $p^{1, n+1}, \ldots, p^{1, l}$.

Second, consider the consumers of generation $t,(t=1,2, \ldots)$, with the constraint that the prices $p^{t 1}, \ldots, p^{t n}$ are already fixed (from previous-period conditions).

Using the relationship between the price levels in periods $t$ and $t+1$, the system of equations associated to a given demand can be written as:

$$
\begin{array}{rlr}
\hat{p}^{t}+\hat{\tau}_{t}^{t} & =\left(p^{t 1}+\tau_{t}^{t 1}\right) R_{t}^{t} & \\
p^{t+1}+\tau_{t}^{t+1} & =\left(p^{t 1}+\tau_{t}^{t 1}\right) R_{t}^{t+1} & \\
p^{t} \omega_{t h}^{t}-p^{t 1} \bar{b}_{t h}^{t} & =\left(p^{t 1}+\tau_{t}^{t 1}\right) W_{t h}^{t} & \text { for } i=1, \ldots, n \\
p^{t} \omega_{t h}^{t}+p^{t+1} \omega_{t h}^{t+1} & =\left(p^{t 1}+\tau_{t}^{t 1}\right) W_{t h} & \text { for } i=1, \ldots, n \\
\sum_{h=1}^{n} \sum_{i=1}^{l} \tau_{t}^{t i} f_{t h}^{t i}\left(R_{t}^{t}, R_{t}^{t+1}, W_{t h}\right)+ & & \\
\left.\left.+\tau_{t-1}^{t i}\right) f_{t-1, h}^{t i}\left(R_{t-1}^{t}, R_{t-1}^{t}\right), W_{t-1, h}\right) & =\delta^{t} &
\end{array}
$$

where the quantities $R_{t}^{t} \in \mathbb{R}^{l-1}, R_{t-1}^{t} \in \mathbb{R}^{l}, W_{t h}^{t}, W_{t h}$ and $\delta^{t}$ are fixed. The system of $2 l-1+2 n+1=2 l+2 n$ equations becomes linear in $3 l$ unknowns, $p^{t, n+1}, \ldots, p^{t, l}$, $p^{t+1,1}, \ldots, p^{t+1, n}, \tau_{t}^{t}$ and $\tau_{t}^{t+1}$.

Introduce the vectors $P_{0}^{t} \in \mathbb{R}^{l-n}$ and $P_{1}^{t+1} \in \mathbb{R}^{n}$ defined by

$$
P_{0}^{t}=\left[\begin{array}{c}
p^{t, n+1} \\
p^{t, n+2} \\
\vdots \\
p^{t, l}
\end{array}\right] \text { and } P_{1}^{t+1}=\left[\begin{array}{c}
p^{t+1,1} \\
p^{t+1,2} \\
\vdots \\
p^{t+1, n}
\end{array}\right] \text {. }
$$

In matrix form, the system can be written as $A_{t} z_{t}=b_{t}$ with

$$
\begin{aligned}
& A_{t}=\left[\begin{array}{ccccccc}
0 & 0 & -\underline{R}_{t}^{t} & I_{n-1} & 0 & 0 & 0 \\
I_{l-n} & 0 & -\bar{R}_{t}^{t} & 0 & I_{l-n} & 0 & 0 \\
0 & I_{n} & -\underline{R}_{t}^{t+1} & 0 & 0 & I_{n} & 0 \\
0 & 0 & -\bar{R}_{t}^{t+1} & 0 & 0 & 0 & I_{l-n} \\
\omega_{t}^{t} & 0 & -W_{t}^{t} \cdot J_{n} & 0 & 0 & 0 & 0 \\
\omega_{t}^{t} & \omega_{t}^{t+1} & -W_{t}^{t+1} \cdot J_{n} & 0 & 0 & 0 & 0 \\
0 & 0 & \sum_{h=1}^{n} f_{t h}^{t 1} & \sum_{h=1}^{n} \hat{f_{t h}^{t}} & & 0 & 0
\end{array}\right]_{2(l+n) \times 3 l}, \\
& \underline{R}_{t}^{t}=\left[\begin{array}{c}
R_{t}^{t 2} \\
R_{t}^{t 3} \\
\vdots \\
R_{t}^{t n}
\end{array}\right]_{n-1 \times 1}, \bar{R}_{t}^{t}=\left[\begin{array}{c}
R_{t}^{t, n+1} \\
R_{t}^{t, n+2} \\
\vdots \\
R_{t}^{t l}
\end{array}\right]_{l-n \times 1}, \underline{R}_{t}^{t+1}=\left[\begin{array}{c}
R_{t}^{t+1,1} \\
R_{t}^{t+1,2} \\
\vdots \\
R_{t}^{t+1, n}
\end{array}\right]_{n \times 1},
\end{aligned}
$$




$$
\begin{aligned}
\bar{R}_{t}^{t+1}= & {\left[\begin{array}{c}
R_{t}^{t+1, n+1} \\
R_{t}^{t+1, n+2} \\
\vdots \\
R_{t}^{t+1, l}
\end{array}\right]_{l+n \times 1}, \omega_{t}^{t}=\left[\begin{array}{cccc}
\omega_{t 1}^{t, n+1} & \omega_{t 1}^{t, n+2} & \ldots & \omega_{t 1}^{t l} \\
\omega_{t 2}^{t, n+1} & \omega_{t 2}^{t, n+2} & \ldots & \omega_{t 2}^{t l} \\
\vdots & \vdots & \vdots & \vdots \\
\omega_{t n}^{t, n+1} & \omega_{t n}^{t, n+2} & \ldots & \omega_{t n}^{t l}
\end{array}\right]_{n \times l-n} } \\
\omega_{t}^{t+1}= & {\left[\begin{array}{cccc}
\omega_{t 1}^{t+1,1} & \omega_{t 1}^{t+1,2} & \ldots & \omega_{t 1}^{t+1, n} \\
\omega_{t 2}^{t+1,1} & \omega_{t 2}^{t+1,2} & \ldots & \omega_{t 2}^{t+1, n} \\
\vdots & \vdots & \vdots & \vdots \\
\omega_{t n}^{t+1,1} & \omega_{t n}^{t+1,2} & \ldots & \omega_{t n}^{t+1, n}
\end{array}\right]_{n \times n}, \text { and } z_{t}=\left[\begin{array}{c}
P_{t}^{t} \\
P_{t}^{t+1} \\
\tau_{t}^{t 1} \\
\tau_{t}^{t 2} \\
\vdots \\
\tau_{t}^{t+1, l}
\end{array}\right] . \text { Let also } W_{t}^{t} \in \mathbb{R}^{n} }
\end{aligned}
$$

and $W_{t} \in \mathbb{R}^{n}$ be the vectors of

individual wealth. The rank of the matrix $A_{t}$ is equal to the rank of the matrix

$$
\left[\begin{array}{ccccc}
0 & 0 & -\underline{R}_{t}^{t} & I_{n-1} & 0 \\
I_{l-n} & 0 & -\bar{R}_{t}^{t} & 0 & I_{l-n} \\
\omega_{t}^{t} & 0 & -W_{t}^{t} \cdot J_{n} & 0 & 0 \\
\omega_{t}^{t} & \omega_{t}^{t+1} & -W_{t} \cdot J_{n} & 0 & 0 \\
0 & 0 & \sum_{h=1}^{n} f_{t h}^{t 1} & & \sum_{h=1}^{n} \hat{f}_{t h}^{t}
\end{array}\right]_{l+2 n \times 2 l}
$$

plus $l$. Some tedious manipulations similar to those performed in the previous section, show that generically the above matrix has maximal rank. Then, for $l=2 n$ the $A_{t}$ matrix has full rank $3 l$. In this case the system has always a solution. The same can be said for $2 n<l$.

Suppose now that $l+1=2 n$. Then the $A_{t}$ matrix is a $3 l+1 \times 3 l$ matrix which has generically maximal rank $3 l$. Consider the square $3 l+1$ matrix associated to the augmented system, $\left(A_{t}, b_{t}\right)$ and let us prove that Rank $\left(A_{t}, b_{t}\right)=3 l+1$. Indeed, the last coordinate of $b_{t}$ is a function of $\delta_{t}$ that can be written as

$$
\delta^{t}-\sum_{h=1}^{n} \sum_{i=1}^{l} \tau_{t-1}^{t i} f_{i t-1}^{t i} .
$$

The determinant of $\left(A_{t}, b_{t}\right)$ is a first degree polynomial expression in $\delta^{t}$. Therefore, to prove that the relevant matrix has full rank for an open and dense set of values of $\delta^{t}$ it is enough that the coefficient of $\delta^{t}$ in the polynomial expression is nonzero, which can be seen to be generically true. Since $\operatorname{Rank}(A)<\operatorname{Rank}(A, b)$, the solution set is empty. Of course, this is the borderline case so the same result holds also whenever $2 n>l+1$. 